Board of Governors of the Federal Reserve System

International Finance Discussion Papers

Number 677

August 2000

\title{
THE DECLINING VOLATILITY OF U.S. EMPLOYMENT: WAS ARTHUR BURNS RIGHT?
}

M. V. Cacdac Warnock and Francis E. Warnock

NOTE: International Finance Discussion Papers are preliminary materials circulated to stimulate discussion and critical comment. References in publications to International Finance Discussion Papers (other than an acknowledgment that the writer has had access to unpublished material) should be cleared with the author or authors. Recent IFDPs are available on the Web at www.bog.frb.fed.us. 
THE DECLINING VOLATILITY OF U.S. EMPLOYMENT:

WAS ARTHUR BURNS RIGHT?

M. V. Cacdac Warnock and Francis E. Warnock ${ }^{\star}$

Abstract: This paper attempts to add to the understanding of changes in the magnitude of business cycle fluctuations by examining disaggregated employment data. Specifically, we use a stochastic variance approach on monthly employment data for the 1946-1996 period to highlight two stylized facts of aggregate U.S. employment - greater volatility in recessions than expansions and reduced volatility since the early 1980s. These patterns are not, however, apparent in each sector of the economy. Asymmetric volatility is only evident in manufacturing and trade; other sectors, such as construction or the narrowly defined services sector, are just as likely to exhibit high volatility in expansions. A general reduction in volatility is evident only in goods-producing sectors; some industries in the broad service-producing sector have become more volatile over time. Our results highlight the close relationship between aggregate and manufacturing volatility, and suggest that to understand why the U.S. business cycle has become more muted, researchers should strive to understand the forces at work that are reducing volatility in the manufacturing sector.

JEL Classification: E32, C1

Keywords: employment, volatility, variability, business cycle

* The authors are economists in the Economics and Research Department of the Mortgage Bankers Association of America (MBA) and the International Finance Division of the Federal Reserve Board, respectively. This paper is based on the first author's dissertation at Fordham University. We received helpful comments from John Burger, Miguel Herce, and H.D. Vinod. The views in this paper are solely the responsibility of the authors and should not be interpreted as reflecting the views of the MBA, the Board of Governors of the Federal Reserve System or of any other person associated with the MBA or the Federal Reserve System. E-mail: veronica_warnock@mbaa.org and frank.warnock@frb.gov 


\section{Introduction}

Recent evidence suggests that the U.S. economy has become more stable over the past 15 years, although the cause is not yet known. For example, McConnell and Quiros (2000) and Kim and Nelson (1999) document breaks in the magnitude of the business cycle in early 1984 . One possible reason for the increased stability is the economy's dramatic post-WWII structural transformation: from 1946 to 1996 employment in the notoriously volatile manufacturing sector fell from 35 percent of U.S. workers to only 15 percent, while the relatively stable services sector grew from 11 to 30 percent of total employment (see Table 1). The broader service-producing sector -- which includes the narrow services, government, transportation and public utilities (TPUT), wholesale trade, retail trade, and finance, insurance, and real estate (FIRE) -- now absorbs about 80 percent of total nonfarm jobs. ${ }^{1}$

Arthur Burns (Burns, 1960) posited long ago that the shift to services from manufacturing would mitigate employment fluctuations. At first glance it seems Burns was indeed correct. But is the shift to services the whole story, or even the most important part? Since this cannot be answered using only aggregate data, we examine disaggregated data of the nine sectors listed in Table 1: the six sectors in the broad service-producing category (listed above) as well as the goods-producing sectors of manufacturing, construction, and mining.

In this paper we estimate employment volatility using a stochastic variance approach. We present graphical evidence of the decline in the volatility of aggregate U.S. employment. We find, like others (e.g., French and Sichel, 1993), that the business cycle is asymmetrical -- aggregate employment fluctuations are greater in recessions than in expansions -- but that volatility has declined in both recessions and expansions, roughly over the period highlighted by McConnell and Quiros (2000) and Kim and Nelson (1999).

To better understand the decline in aggregate volatility, we examine volatility patterns in the nine major sectors of the U.S. economy. We find that the volatility of employment in the manufacturing sector, specifically in durable goods manufacturing, is strikingly similar to aggregate volatility. This suggests that more is at work than just a movement towards relatively stable sectors -- manufacturing, a sector that historically has been very volatile, has itself become more stable. ${ }^{2}$ This provides more evidence that the durable goods manufacturing sector plays an important role in overall employment volatility, notwithstanding its declining share in aggregate employment. To understand the recent decline in overall volatility, and to

1 The narrow services sector consists of hotels and other lodging places; personal services; commercial and trade schools and employment agencies; business services; miscellaneous repair services; motion pictures; amusement and recreation services; health services; legal services; educational services, nec; membership organizations; miscellaneous professional services; and private households.

2 The job creation and destruction literature comes to a similar conclusion; see Ritter (1994). 
determine whether it is likely to continue, future work should concentrate on forces affecting durable goods manufacturing. An initial discussion of two such forces -- just-in-time inventories and improved monetary policy -- is made here.

The sectoral approach also yields interesting results about the service-producing sectors. We find, as alluded to in Lebow and Sichel (1995), that not all industries in these sectors exhibit declining employment volatility. The pattern of declining volatility in both recessions and expansions that is evident in aggregate and manufacturing employment is not seen in wholesale and retail trades, narrow services, and TPUT. In fact, one industry, FIRE, shows a trend toward increased volatility: volatility in the last recession and the current expansion is higher than at any other time in the post-war period.

The paper is organized as follows. The next section presents the methodology, discusses the data, and analyzes diagnostics from the estimations. In Section III, graphical representations of the estimated volatilities are presented and results linking manufacturing volatility to aggregate volatility are discussed in greater detail. In Section IV candidate reasons for the declining manufacturing volatility are presented. Conclusions are in Section V.

\section{Methodology and Data}

There is evidence based on summary statistics that the post-WWII structural shift in U.S. employment has had a stabilizing effect on overall employment. The works of Fuchs (1968), Urquhart (1981), and Zarnowitz and Moore (1986) -- which calculate the theoretical average decline in aggregate employment in recessions had employment shares been constant -- suggest that the U.S. economy is more stable with its current composition. Our methodology attempts to go past this truism by looking at volatility patterns within sectors, and we find evidence that the structural shift towards less volatile sectors is not the whole story.

\section{Methodology}

The serially correlated changes in the volatility of economic time series can be modeled by using a stochastic variance (SV) approach. A simple SV model used by Breidt and Carriquiry (1996), Harvey et. al. (1994), and Harvey and Shephard (1993) is given by

$$
\begin{array}{lll}
y_{t}=\sigma_{t} \epsilon_{t}=\sigma \epsilon_{t} \exp \left(1 / 2 h_{t}\right), & \epsilon_{t} \sim \operatorname{IID}(0,1), & t=1, \ldots, T \\
h_{t+1}=\rho h_{t}+\eta_{t}, & \eta_{t} \sim \operatorname{NID}\left(0, \sigma_{\eta}^{2}\right), & |\rho|<1
\end{array}
$$

The error term in the observation or measurement equation (1), $\varepsilon_{t}$, is an identically distributed random disturbance. The standard deviation, $\sigma_{t}$, equals $\sigma \exp \left(1 \frac{1}{2} h_{t}\right)$, where $\sigma$, a positive constant, is a scale factor that 
includes the effect of a constant term in $h_{t}$. In the state or transition equation (2), the unobserved volatility, $h_{t}$, is a time-dependent component of $y_{t}$ that is modeled to follow a standard Gaussian autoregressive process. Note that $h_{t}$ equals $\left(\log \sigma_{t}^{2}\right)$ or $\log \left[\exp \left(1 / 2 h_{t}\right)\right]^{2}$ and the disturbance $\eta_{t}$ is uncorrelated with $\varepsilon_{t}$ and is assumed to be i.i.d. with mean zero and variance equal to $\sigma_{\eta}^{2}$.

The quasi-maximum likelihood approach applies a simple method of estimating the SV model. The initial step is to put the dynamic model into a state-space form to capture the dynamics of an observed variable $y_{t}$ in terms of the unobserved component $h_{t}$. If the observations are squared and their logs are taken, the result is a linear transformation of equation (1),

$$
\log y_{t}^{2}=\log \sigma^{2}+\log \left(\exp \left(1 / 2 h_{t}\right)\right)^{2}+\log \epsilon_{t}^{2}
$$

which can be rewritten as,

$$
x_{t}=\log y_{t}^{2}=\kappa+h_{t}+\xi_{t}, \quad t=1, \ldots, T
$$

where,

$$
\begin{aligned}
& \kappa=\log \sigma^{2}+E\left(\log \epsilon_{t}^{2}\right) \\
& \xi_{t}=\log \epsilon_{t}^{2}-E\left(\log \epsilon_{t}^{2}\right) .
\end{aligned}
$$

The disturbance term in (3) is $\xi_{t}$, which is i.i.d. (but not Gaussian) with mean zero and variance $\sigma_{\xi}^{2}$; both the mean and the variance depend on the distribution of $\varepsilon_{t}$. There is no need to assume a specific distribution for $\varepsilon_{t}$.

Equations (2) and (3) make up the linear state-space representation for the dynamic behavior of $y$. The state-space set-up allows for a Kalman filter estimation of three parameters: $\rho, \sigma_{\eta}^{2}$ and $\sigma_{\varepsilon}^{2}$, and evaluation of the likelihood. The disturbances $\xi_{t}$ and $\eta_{t}$ are treated as though they were normal; the Kalman filter provides approximate results to the true nonlinear optimal filter. The quasi-maximum likelihood (QML) estimates that maximize the likelihood function under the assumption of a Gaussian process when the true data are non-Gaussian will yield reasonable estimates of the parameters when the innovations are not i.i.d. Gaussian. The asymptotic distribution of the QML estimator of $\Psi=\left(\rho, \sigma_{\eta}^{2}\right)$ is given in Ruiz (1994), based on the results in Dunsmuir (1979). Estimation is straightforward using STAMP; see Koopman et. al. (1995). 
The efficiency of QML will be affected by the extent of the departure from Gaussianity in $\xi_{t}$, the disturbance term in the measurement equation (3). In practice, Ruiz (1994) shows that as $\sigma_{\eta}^{2}$ approaches zero and $h_{t}$ is dominated by the $\xi_{t}$ error term, the normality approximation worsens.

The smoothed estimate of the unobserved volatility $h_{t}$ is also computed using the Kalman filter technique. The smoothing algorithm uses all information in the sample to form inference about the unobserved state $h_{t}$ at any date. The plot of the smoothed estimate of $h_{t}$ will show how the volatility of the series changes over time. As noted above, due to the non-Gaussianity of $x_{t}$, or $\log \left(y_{t}^{2}\right)$, the Kalman filter will yield minimum mean square linear estimators of $h_{t}$, not minimum mean square estimators.

\section{Inliers}

Since the measurement equation is a log-linear transformation, small values of $y_{t}$, termed "inliers," present a two-fold problem. First, the log transformation simply cannot be carried out on observations with values of zero because $\log 0^{2}=-\infty$. Second, taking the logarithm of the square of any number near zero results in a large negative outlier and greatly influences the estimation.

There are many methods that address the problem; we will use a transformation suggested by Wayne A. Fuller and analyzed by Breidt and Carriquiry (1996). ${ }^{3}$ The Fuller transformation is

$$
\log y_{t}^{2} \cong \log \left(y_{t}^{2}+c s_{y}^{2}\right)-c s_{y}^{2} /\left(y_{t}^{2}+c s_{y}^{2}\right), \quad t=1, \ldots, T
$$

where $s_{y}{ }^{2}$ is the sample variance of $y_{t}$ and $c$ is a small number, say 0.02 . The transformed variable $\log y_{t}^{2}$ will therefore have a lower bound equal to $\log \left(c s_{y}{ }^{2}\right)-1$. The effect of the transformation is data-driven; observations that are near zero or equal to zero are modified depending on the degree of inlying. For large $y_{t}^{2}$ the effect of the transformation is negligible.

Breidt and Carriquiry (1996) found that the transformation reduced both the excess kurtosis and skewness of the disturbance term in the measurement equation, $\xi_{t}$. Furthermore, the transformation was shown to substantially improve the sampling performance of the QML estimator, which is not surprising since the transformed error term is closer to normal.

\section{Data}

${ }^{3}$ See also Fuller (1996), example 9.3.2, pp. 495-497. 
The data that are used to estimate sectoral employment volatility are deviations from mean growth rates. ${ }^{4}$ The underlying data consist of monthly, post-WWII (1946-1996) employment figures for the nine major industrial sectors (listed in Table 1) of the U.S. economy. The sample size, $T$, is 611. Since the SV technique is usually used on higher frequency data, we discuss in this section the suitability of the employment data for this technique.

In a simple sense, data estimated by the SV technique should satisfy two basic requirements. The first requirement is that the variance of the series under examination should have changed over the sample. CUSUMSQ tests on the data, reported in Warnock (1998), show that the individual employment growth rates display evidence of time-varying volatility. ${ }^{5}$ Since we demean the data, the mean growth rates should be relatively constant. CUSUM tests, also reported in Warnock (1998), show that the mean growth rates of most of the series have not changed significantly over the sample period. However, the tests also show that government employment had a higher mean growth rate in the 1960s; construction and wholesale trade had higher mean growth rates at the beginning of the sample; and FIRE had a lower mean growth rate in the last 15 years. Of these, the divergence for FIRE is the most notable because it occurs at the end of the sample, a time period that we are particularly interested in analyzing.

The second basic requirement for the SV technique is that the data should show evidence of volatility clustering. Figure 1 presents plots of growth rates for the aggregate and the nine major sectors. The graphs suggest, as CUSUMSQ tests indicate, that the variances of many of the series have changed over the sample. Furthermore, volatility clustering is easily discernible for total nonfarm, government, wholesale trade, retail trade, and FIRE; that is, months of large movements are followed by months of large movements, and months of small movements tend to be followed by months of small movements. For these series, the first decade after World War II is marked by wild fluctuations, followed by relatively tamed movements in the mid to late 1960s. A different pattern, but nevertheless showing volatility clustering, appears for construction, manufacturing, transportation and public utilities (TPUT), construction, and services. Mining displays a unique behavior as there is no evidence of volatility clustering -- very large monthly changes are isolated, not clustered.

Evidence of time-dependence of the second moments of our time series is provided by Box-Ljung $Q$ statistics. Significant correlations in the lags of $y_{t}^{2}$ is a strong indication of time-dependence in the

${ }^{4}$ Alternatively, the residuals from an AR(p) regression on the log first-differenced data, which are i.i.d. and represent growth rates adjusted for cyclical movements, could be analyzed.

${ }^{5}$ CUSUM and CUSUMSQ were proposed by Brown, Durbin, and Evans (1975) and are discussed in Johnston (1984), Harvey (1990), and Greene (1997). 
variances of $y_{t}$. Table 2 shows the Box-Ljung $Q$ statistics on $y_{t}^{2}$. The $Q$ statistics, which have an asymptotic $\chi_{p}^{2}$ distribution with $p$ degrees of freedom equaling the first $p$ lags if $y_{t}^{2}$ are uncorrelated, are reported for $p$ $=3,6,12,24$. If there is no serial dependence in the squares of $y_{t}$, the statistics should not exceed the critical values. All of the squared series have large $Q$ stats and therefore exhibit significant serial autocorrelation at short and extended lag lengths, indicating time-dependence in the variances of the growth rates.

The evidence discussed in this section suggests that it is suitable to use the SV approach on monthly employment data, because there is evidence of nonlinearities in the squares of the growth rates. We must recognize, however, that the approach has shortcomings. The primary limitation of our application of the SV technique is that, by working directly with the square of the series, we do not model dynamics in the first moments of the underlying series. This appears to be relevant in the employment data set because the BoxLjung $Q$ statistics (Table 2) show that there are significant nonlinearities in the first moments. We note this shortcoming, but also note that the SV approach has been used on data series that exhibit dynamics in the first moments; see Harvey et al. (1994, p. 253). Moreover, the SV technique has an appealing feature in that it is relatively robust to departures from the underlying assumptions; see Breidt and Carriquiry (1996). ${ }^{6}$

\section{Diagnostics}

The stochastic variance state space model, equations (2) and (3), is estimated using STAMP, which uses the BFGS quasi-Newton method to maximize the likelihood criterion. To avoid inliers, the series (deviations from mean growth rates) are transformed using the Fuller method described in the previous section. For each of the ten univariate estimations, convergence was very strong based on criteria presented in STAMP--at the final iteration of the BFGS procedure, the likelihood function and all parameter values changed by less than $10^{-7}$ and the gradient was less than $10^{-7}$.

Results of the QML estimation are presented in Table 3. For four sectors -- total nonfarm, government, wholesale trade, and FIRE -- estimates of the AR(1) parameters for the smoothed volatility series are greater than 0.9. Retail trade and manufacturing also have high $\mathrm{AR}(1)$ parameters at 0.88 and 0.86 , respectively. All series but government have AR(1) estimates that are greater than two standard deviations from one. The residuals of most series show no serial autocorrelation, as indicated by the Box-Ljung $Q$ statistics of the residuals, calculated as

${ }^{6}$ The analysis could also be done using a GARCH estimation technique, which has the advantage of accounting for dynamics in the first moments. Doing so does not substantially alter the main results of the paper, the declining volatility of aggregate employment and its close association with volatility in the manufacturing sector; the correlation between the implied volatilities in the two series is 0.89 . 


$$
Q(p, q)=T(T+2) \sum_{\tau=1}^{p}\left(\mathrm{r}_{\tau}^{2} / T-p\right) .
$$

where $p$ equals the number of lags, $q$ equals $p+1$ minus the number of parameters, $T$ is the number of observations, and $r_{\tau}$ is the autocorrelation at lag $\tau$. Three series -- construction, wholesale trade, and retail trade -- show residual serial correlation at the 95 percent level, indicating that the dynamics of these series are less than adequately captured by the SV model. In general, though, the $Q$ statistics indicate that the SV model is adequately capturing the dynamics of the series.

As noted above, the efficiency of the QML estimation is affected by the extent of the departure from normality of the error term in equation (3). Table 4 shows chi-squared tests of skewness, excess kurtosis, and normality for the error term. While we can reject normality of the errors for many of the sectors, we cannot reject normality for two series that are important to our analysis -- manufacturing and total employment volatility.

The diagnostics presented in Tables 3 and 4 suggest that in our analysis the SV approach is most suitable for the manufacturing sector, aggregate employment, and, somewhat surprisingly, the government sector.

\section{Patterns in Aggregate and Sectoral Employment Volatility}

In this section we present graphs of employment volatility in the aggregate economy, as well as in the three goods-producing and six service-producing sectors. We show that the main volatility patterns in the aggregate economy - higher volatility in recessions than in expansions and declining volatility in both expansions and recessions - do not occur in most sectors of the economy, but are plainly evident in the manufacturing sector. Since our evidence suggests the manufacturing sector has an important role in overall volatility, we investigate it further by presenting volatility in both employment and output in the durable goods subsector.

We begin by discussing Figures 2 (a) - 2(j), which consist of the estimated unobserved volatility, $\tilde{h}_{t \mid T}$, of sectoral employment as given by a Kalman smoothing algorithm. Recession bars in the graphs are based on NBER business cycle reference dates.

\section{Volatility of Aggregate Employment}

Two stylized facts are evident in Figure 2(a). First, aggregate employment volatility is asymmetric with respect to the business cycle. This is not a new finding; the results of French and Sichel (1993), who used an asymmetric exponential GARCH approach, suggest that volatility is higher in recessions than in 
expansions. Figure 2(a) merely show this in another way. From the figure, we see that spikes in aggregate employment volatility tend to occur during recessions. In each of the nine postwar recessions, aggregate employment volatility increased sharply, whereas spikes in volatility during expansions occur only infrequently. The typical pattern is, not surprisingly, one in which firms slowly but steadily add workers in expansions, then cut back during recessions.

To be sure, periods of increased volatility occasionally occur in expansions. Examples are the periods of 1952, the mid-1960s, and 1983. In mid-1952, a temporary, sharp mid-expansion decrease in manufacturing employment resulted in a spike in aggregate employment volatility. In the mid-1960s, the increased volatility, which coincided with strong employment increases in government and durable goods manufacturing, was due to the excessive fiscal stimulus of the Kennedy tax cuts and the Vietnam War buildup. Over the two-year period from July 1964 to June 1966, aggregate employment increased an average of almost 250,000 per month. ${ }^{7}$ More than half of this average monthly increase was due to strong increases in two sectors, manufacturing and government. Over the two-year period, manufacturing added an average of 85,000 workers per month, three-quarters of which were in durable goods, while monthly increases in the government sector averaged over 50,000. In late-1983, the increase in volatility appears to have been due to two forces. The September 1983 peak in volatility coincided with large strikes by workers in two utility companies, AT\&T and Western Electric. However, the general pattern of the spike in aggregate volatility corresponds with the pattern in the manufacturing sector, which added a robust 100,000 workers per month in the twelve-month period from May 1983 to April 1984.

The second stylized fact evident in Figure 2(a) is that employment volatility has decreased over time. This decreased volatility appears to coincide with the findings of McConnell and Quiros (2000) and Nelson and Kim (1999), who point to an early-1984 break in volatility in real GDP growth. The relationship between the findings of those two studies and of this paper is clearest when examining the pattern of volatility in expansions. After the spike in volatility in late 1983 (discussed above), employment volatility in the last two expansions has been markedly lower than in previous expansions.

Figure 2(a) also shows that declining volatility is apparent in recessions, too. While recessions tend to be more volatile than expansions, a downward trend in the volatility of recessions is nevertheless apparent, although it should be noted that the short recessions of 1970 and 1980 had the lowest recession-period employment volatility.

\footnotetext{
${ }^{7}$ Put another way, over the two-year period employment increased 10 percent; by comparison, two-year employment gains in the current expansion have averaged around five percent.
} 
To better understand the nature of aggregate employment volatility, in the next two subsections we investigate volatility in the nine major sectors of the economy, beginning with the three goods-producing sectors.

\section{Volatility of Employment in Goods-Producing Sectors}

Graphs of employment volatility in the three goods-producing sectors - construction, manufacturing, and mining - are shown in Figures 2(b) - 2(d). Volatility in two of the sectors, construction and mining, bears little resemblance to aggregate volatility. Contrary to the asymmetry found in aggregate employment, employment in these sectors is just as likely to be volatile in expansions as in recessions. On the other hand, there is some evidence that the volatility of construction and mining has declined over time.

More striking is a comparison of Figures 2(a) and 2(c), which shows that while employment volatility in the manufacturing sector has been greater than aggregate employment volatility, the two exhibit very similar patterns. Both tend to spike in recessions and be relatively calm in expansions. Moreover, as mentioned in the previous subsection, increases in aggregate volatility that occur during expansions, such as in the mid-1960s, occur in manufacturing as well. All of this suggests that the manufacturing sector despite its decline to a mere 15 percent share of total employment - contributes disproportionately to overall volatility.

\section{Volatility of Employment in Service-Producing Sectors}

In general, employment volatility in service-producing sectors, Figures 2(e) - 2(j), is lower than in goodsproducing sectors, and is less closely related to overall employment volatility than is the manufacturing sector. The decrease in volatility that is evident in aggregate and manufacturing employment is not seen in the service-producing sectors. In fact, volatility in FIRE, Figure 2(i), has been higher in the current expansion than at any time in the past 40 years. Moreover, the asymmetry of employment volatility is not as evident service-producing sectors, with the exception of wholesale trade (Figure 2(g)). In the narrow services sector (Figure 2(j)), for example, spikes in employment volatility are just as likely to occur in expansions as in recessions.

\section{A Closer Look at Volatility in the Manufacturing Sector}

Figure 2 suggests that aggregate employment fluctuations are to a large extent those of the manufacturing sector. The implication is clear. To understand the recent dampening of the business cycle, we should concentrate on understanding forces affecting the manufacturing sector. As an initial step, we examine volatility in a subsector of manufacturing, durable goods manufacturing, as well as in industrial production. 
First, we examine employment volatility in the durable goods manufacturing sector. ${ }^{8}$ As expected, the top panels of Figure 3 show that employment volatility in the overall manufacturing sector is closely related to employment volatility in durable goods manufacturing. ${ }^{9}$ The closeness of the relationship is striking, as the two volatility series are almost identical; the simple correlation is 0.97 . This suggests, as noted by Warnock (1998), that to understand patterns in manufacturing employment volatility and, hence, aggregate employment volatility, one should concentrate on the durable goods manufacturing sector.

Next, we investigate whether the patterns in the volatility of manufacturing employment are also found in manufacturing output. While hours worked and productivity vary over time and over the course of the business cycle, output and employment are almost surely closely related. The bottom panels of Figure 3 show that the volatility of manufacturing output is indeed similar to the volatility of manufacturing employment; the simple correlation is 0.78 . The main volatility features of aggregate and manufacturing employment -- the reduction in volatility over time and the higher volatility during recessions (with the possible exceptions of the 1948-49 and 1969-70 recessions) -- are also evident in manufacturing output. Thus, it can be hypothesized that manufacturing employment is volatile because demand for manufactured goods is volatile. ${ }^{10}$ Further, the volatility of employment in manufacturing of durable goods is very similar to overall manufacturing employment volatility. The same relationship is evident between durable goods output and total manufacturing output. Note, finally, that durable goods output has volatility patterns similar to those in overall manufacturing employment. This suggests that to ascertain why manufacturing employment and, by extension, overall employment, have become less volatile over time, we need to understand why the volatility of durable goods output has declined.

\section{Possible Reasons for Declining Volatility in the Manufacturing Sector}

\footnotetext{
${ }^{8}$ Estimation results for all series discussed in this section are in Table 5. The results are quite similar to those reported in Table 3 for manufacturing employment. AR(1) coefficients are between 0.80 and 0.86 , and the Box-Ljung $Q$ tests for residual serial autocorrelation are borderline.

9 The volatility pattern in nondurable goods manufacturing, not shown here, bears almost no resemblance to the pattern in overall manufacturing.

10 The hypothesis that employment volatility is influenced by the demand for the product in a sector could be extended to other sectors as well. If services employment displays low volatility, services production is likely to be less volatile as well. Unfortunately, investigating this in the stochastic variance framework is not possible. The model requires a very large number of observations, but monthly production data are limited to industrial sectors. Data on GDP by industry are available only annually.
} 
In this section we investigate two possible sources for the recent increased stability in the manufacturing sector. The first concerns the way the sector reacts to external shocks, while the second concerns the shocks that hit the sector.

\section{Just-in-Time Inventory Control}

It is possible that the recent stability of the manufacturing sector is due to improvements in the way the sector reacts to external shocks. Spending on manufactured goods -- especially durable goods -- is interest-sensitive and hence quite cyclical. If firms have high inventories relative to sales, an unexpected decrease in demand would likely result in a sharp slowdown in production and employment growth as firms attempt to sell off inventories. Conversely, a less volatile scenario is one in which firms operate on lower inventory-to-sales ratios and hence do not have to react as sharply to unanticipated changes in demand.

According to National Association of Purchasing Management surveys, inventory management methods have indeed changed since the early 1980s; see Allen (1995). Modern technology and just-in-time production techniques facilitate better management of production with respect to sales, and thus should allow the manufacturing sector to carry relatively lower inventories. There is indeed some evidence of a downward trend in manufacturing inventory-to-sales ratios. Figure 4 shows that the spike in the inventory-to-sales ratio in the 1990-91 recession was less severe than in past recessions, and that the ratio has reached a lower level in the current expansion than it has in the past 20 years. Whether the figure exhibits a secular decline is, however, less clear.

Not surprisingly (given the pattern in Figure 4), empirical evidence on the effect of new inventory management techniques on the business cycle is not yet conclusive. Allen (1995) notes that while changes in inventory control have lowered inventory-to-sales ratios, the change in inventory investment still accounted for nearly 60 percent of the overall change in real GDP in the last recession. Filardo(1995), using a vector autoregression method, concludes that there is no evidence of a reduced role for inventories in the business cycle. However, Little (1992) argues that there may be an insufficient sample size to empirically evaluate the effect of the new inventory management techniques, especially as they have not yet saturated

the market. While it appears that just-in-time inventory control methods allow manufacturing firms to operate with lower inventories - and, perhaps, to adjust employment less sharply in the face of unexpected changes in product demand - there is not yet conclusive empirical evidence.

\section{Improved Monetary Policy}

The manufacturing sector has been buffeted by many shocks, including shocks that affect its competitiveness - such as shocks to productivity, input prices, or exchange rates - and shocks that influence demand for its 
products, such as changes in monetary policy. While the former are likely important, in this section we focus on the latter.

The hypothesis that improved monetary policy has played a role in the reduced volatility of the manufacturing sector depends on two premises. First, monetary policy must have improved since the early 1980s. Second, because the decline in volatility is not evident in all sectors (the service-producing sectors, in particular), monetary policy must have differential effects across sectors. We discuss these in turn.

Some researchers believe Fed policy has indeed become more stabilizing. While an empirical answer to that question requires a structural model and is beyond the scope of this paper, Mussa (1994), for example, contends that prior to the 1980s monetary policy was prone to being overly loose in expansions. When inflation inevitably increased, policy had to be tightened quickly and severely, resulting in slowdowns or outright recessions. Mussa contends that since 1980 the Fed is more inclined to engage in preemptive strikes to eliminate inflationary pressures before they get out of control - hence the mid-expansion tightenings of monetary policy in 1984, 1987, 1988-89, and 1994. It is possible, therefore, that the reduced willingness of the Fed to fan the boom-bust cycle is one factor helping to reduce employment volatility.

If monetary policy has indeed become more stabilizing, for it to be an important factor in the declining volatility, it would also have to affect manufacturing differently than other sectors. Indeed, purchases of durable goods are particularly sensitive to interest rate changes that affect borrowing costs for consumers and businesses alike, and ample empirical evidence of the differential effects of monetary policy exists. Using U.K. data, Ganley and Salmon (1997) show that the manufacturing sector reacts faster and greater than other sectors to shocks in monetary policy. Similar evidence exists for the United States; Carlino and DeFina (1998) find that the regions in the United States that have a higher concentration of manufacturing tend to react faster and more strongly to changes in monetary policy. Finally, Christiano, Eichenbaum, and Evans (1996) present evidence that a monetary contraction leads to increased manufacturing inventories, presumably because sales decline unexpectedly.

In summary, preliminary evidence suggests that it is plausible that better inventory control methods and improved monetary policy have played a role in the recent stability of the manufacturing sector. Further work is needed to quantify these effects.

\section{Conclusion}

While Arthur Burns was to some extent correct -- the transformation of U.S. employment from volatile manufacturing to stable services has undoubtedly mitigated employment fluctuations - we present evidence suggesting that a key catalyst is the declining employment volatility in the manufacturing sector itself. We 
discuss two possible reasons for the increased stability of the manufacturing sector, just-in-time inventory methods and improved monetary policy.

The implications of our findings are as follows. First, to understand changes in volatility in the U.S. economy, we must understand changes affecting the manufacturing sector. Relatedly, a sectoral approach may well deepen our understanding of macroeconomic issues. Finally, our graphical evidence should serve to remind us that recessions and expansions are indeed different: Not only should empirical researchers be aware of one-time breaks in volatility, as suggested by McConnell and Quiros (2000), but we should also account for asymmetries in the business cycle. Further work needs to be done to disentangle candidate sources of the decline in volatility, at both the theoretical and empirical levels. 


\section{BIBLIOGRAPHY}

Allen, Donald S. "Changes in Inventory Management and the Business Cycle." Federal Reserve Bank of St. Louis Review, July/August 1995, 77(4), pp. 17-26.

Breidt, F. Jay, and Alicia L. Carriquiry. "Improved Quasi-Maximum Likelihood Estimation for Stochastic Volatility Models." in Jack C. Lee, Wesley O. Johnson, and Arnold Zellner, eds. Modelling and Prediction: Honoring Seymour Geisser. New York: Springer-Verlag, 1996.

Brown, R.L., J. Durbin, and J.M. Evans. "Techniques for Testing the Constancy of Regression Relationships over Time.” Journal of Royal Statistical Society B, 1975, 37, pp. 149-163.

Burns, Arthur F. "Progress Towards Economic Stability." The American Economic Review, March 1960, 50(1), pp. 2-19.

Carlino, Gerald, and Robert DeFina. "The Differential Effects of Monetary Policy Shocks on Regional Economic Activity." The Review of Economics and Statistics, November 1998, 80(4), pp. 572-87.

Christiano, Lawrence J., Martin Eichenbaum, and Charles Evans. "The Effects of Monetary Policy Shocks: Evidence from the Flow of Funds." The Review of Economics and Statistics, February 1996, 78(1), pp. 16-34.

Dunsmuir, W. "A Central Limit Theorem for Parameter Estimation in Stationary Time Series and its Applications to Models for a Signal Observed White Noise.” Annals of Statistics, 1979, 7, pp. 490-506.

Filardo, Andrew J."Recent Evidence on the Muted Inventory Cycle." Federal Reserve Bank of Kansas City Economic Review, Second Quarter 1995, 80(2), pp. 27-43.

French, Mark W., and Daniel E. Sichel. "Cyclical Patterns in the Variance of Economic Activity." Journal of Business and Economics, January 1993, 11(1), pp. 113-19.

Fuchs, Victor R. The Service Economy. NBER no. 87, General Series. New York: Columbia University Press, 1968.

Fuller, Wayne A. Introduction to Statistical Time Series, 2d ed. New York: John Wiley, 1996.

Ganley, Joe, and Chris Salmon. "The Industrial Impact of Monetary Policy Shocks: Some Stylized Facts." Bank of England Working Paper Series No. 68, September 1997.

Greene, William H. Econometric Analysis, 3d ed. New Jersey: Prentice-Hall, Inc., 1997. 
Harvey, A.C. The Econometric Analysis of Time Series, United Kingdom: BPCC Wheaton Ltd, 1990.

Harvey, A.C., Esther Ruiz, and Neil Shephard. "Multivariate Stochastic Variance Models." Review of Economic Studies, 1994, 61, pp. 247-264.

Harvey, A.C., and Neil Shephard. "Estimation and Testing of Stochastic Variance Models." STICERD Econometrics Discussion Paper EM/93/268. U.K.:LSE, 1993.

Johnston, J. Econometric Methods, 3d ed. USA: McGraw-Hill, 1984.

Kim, C.J., and C. Nelson. "Has the U.S. Economy Become More Stable? A Bayesian Approach Based on a Markov-Switching Model of the Business Cycle." Review of Economics and Statistics, 1999, 81(4) pp. 608-617.

Koopman, Siem J., Andrew C. Harvey, Jurgen A. Doornik, and Neil Shephard. STAMP 5.0: Time Series Analyser, Modeller and Predictor. London: Chapman \& Hall, 1995.

Lebow, David E., and Daniel E. Sichel. "Is the Shift Toward Employment in Services Stabilizing?." in Patrick T. Harker, The Service Productivity and Quality Challenge. International Studies in the Service Economy, Volume 5. Boston: Kluwer Academic Publishers, 1995, pp. 81-112.

Little, Jane Sneddon. "Changes in Inventory Management: Implications for the U.S. Recovery." Federal Reserve Bank of Boston New England Economic Review, November/December 1992, pp. 37-65.

McConnell, Margaret, and Gabriel Perez Quiros. "Output Fluctuations in the United States: What Has Changed Since the Early 1980s?” American Economic Review, forthcoming 2000.

Mussa, Michael. "Monetary Policy." in Martin Feldstein, ed. American Economic Policy in the 1980s. Chicago: Chicago University Press, 1994, pp. 81-145.

Ritter, Joseph A. "Job Creation and Destruction: The Dominance of Manufacturing." Federal Reserve Bank of St. Louis Review, September/October 1994, pp. 3-11.

Ruiz, Esther. "Quasi-maximum Likelihood Estimation of Stochastic Volatility Models." Journal of Econometrics, 1994, 63, pp. 289-306.

Urquhart, Michael. "The Service Industry: Is it Recession-proof?.” Monthly Labor Review, October 1981, pp. $12-18$.

Warnock, M.V. Cacdac. "An Empirical Study of U.S. Employment Fluctuations." Ph.D. dissertation, Fordham University, 1998. 
Zarnowitz, Victor, and Geoffrey H. Moore. "Major Changes in Cyclical Behavior." in Robert A. Gordon, The American Business Cycle: Continuity and Change. Chicago: The University of Chicago Press, 1986, pp. 519-582. 
Table 1--Distribution of Nonfarm Employment

\begin{tabular}{lccc}
\hline & 1946 & & 1996 \\
\cline { 2 - 3 } Service-producing & Percent & Percent \\
Services & 58.6 & 79.6 \\
Trade (Wholesale and Retail) & 11.3 & 28.8 \\
Government & 20.1 & 23.5 \\
Finance, Insurance, and Real Estate (FIRE) & 13.5 & 16.3 \\
Transportation and Public Utilities (TPUT) & 4.0 & 5.8 \\
& 9.8 & 5.2 \\
Goods-producing & & \\
Manufacturing & 41.4 & 20.4 \\
Construction & 35.3 & 15.4 \\
Mining & 4.0 & 4.5 \\
\hline
\end{tabular}

Note: Due to rounding, parts may not sum to whole. 
TABLE 2-- BoX-LJUNG Q STATISTICS

\begin{tabular}{lrrrr}
\hline & $\mathrm{Q}(3)$ & $\mathrm{Q}(6)$ & $\mathrm{Q}(12)$ & $\mathrm{Q}(24)$ \\
\hline \hline & & $y_{t}{ }^{2}$ & & \\
\cline { 2 - 5 } Total nonfarm & 124.00 & 176.48 & 193.24 & 209.43 \\
Government & 57.41 & 74.73 & 86.84 & 111.08 \\
Mining & 141.18 & 242.95 & 243.43 & 244.06 \\
Construction & 78.81 & 79.11 & 81.10 & 129.02 \\
Manufacturing & 257.68 & 261.05 & 261.59 & 262.44 \\
Transportation\&PUtilities & 149.00 & 149.05 & 149.14 & 149.40 \\
Wholesale trade & 138.41 & 160.43 & 265.47 & 393.26 \\
Retail trade & 75.55 & 76.14 & 98.76 & 210.41 \\
FIRE & 47.22 & 59.84 & 162.55 & 167.44 \\
Services & 27.08 & 62.17 & 78.52 & 98.43 \\
\hline Critical 5 percent values & 7.81 & 12.59 & 21.03 & 36.42 \\
\hline
\end{tabular}

Notes: $y_{t}=\left(\log n_{t}-\log n_{t-1}\right)-1 / T \sum_{t=1}^{T}\left(\log n_{t}-\log n_{t-1}\right)$ where $n_{t}$ is the employment series at time $t$. 
TABLE 2--Continued

\begin{tabular}{lcccc}
\hline & $\mathrm{Q}(3)$ & $\mathrm{Q}(6)$ & $\mathrm{Q}(12)$ & $\mathrm{Q}(24)$ \\
\hline \hline & \multicolumn{4}{c}{$y_{t}$} \\
\cline { 2 - 4 } Total nonfarm & 218.18 & 320.37 & 341.55 & 404.65 \\
Government & 32.84 & 85.18 & 151.74 & 188.63 \\
Mining & 75.57 & 125.93 & 126.44 & 140.60 \\
Construction & 30.01 & 57.79 & 73.08 & 99.54 \\
Manufacturing & 158.48 & 218.00 & 230.83 & 305.47 \\
Transportation\&PUtilities & 72.85 & 74.75 & 78.25 & 80.91 \\
Wholesale trade & 234.21 & 355.75 & 455.33 & 466.63 \\
Retail trade & 50.46 & 87.48 & 153.02 & 171.98 \\
FIRE & 332.30 & 546.95 & 704.82 & 857.86 \\
Services & 156.43 & 254.96 & 317.53 & 344.49 \\
\hline Critical 5 percent values & 7.81 & 12.59 & 21.03 & 36.42 \\
\hline
\end{tabular}

Notes: $y_{t}=\left(\log n_{t}-\log n_{t-1}\right)-1 / T \Sigma_{t=1}^{T}\left(\log n_{t}-\log n_{t-1}\right)$ where $n_{t}$ is the employment series at time $t$. 
TABLE 3--QUASI-MAXIMUM LIKELIHOOD ESTIMATION RESULTS UNIVARIATE STOCHASTIC VOLATILITY MODELS

FULLER-TRANSFORMED EMPLOYMENT GROWTH RATES

\begin{tabular}{|c|c|c|c|c|}
\hline & $\rho$ & $\sigma_{\eta}^{2}$ & $\log \mathrm{L}$ & $\mathrm{Q}(23,21)$ \\
\hline Total nonfarm & $\begin{array}{c}.9240 \\
(.0298)\end{array}$ & $\begin{array}{l}0.2746 \\
(.1175)\end{array}$ & -298.256 & 23.28 \\
\hline Government & $\begin{array}{c}.9418 \\
(.0302)\end{array}$ & $\begin{array}{l}0.1057 \\
(.0641)\end{array}$ & -331.874 & 18.01 \\
\hline Mining & $\begin{array}{c}.6155 \\
(.1080)\end{array}$ & $\begin{array}{l}1.2889 \\
(.5203)\end{array}$ & -227.470 & 21.24 \\
\hline Construction & $\begin{array}{c}.6317 \\
(.1038)\end{array}$ & $\begin{array}{l}1.2688 \\
(.5092)\end{array}$ & -374.134 & 55.10 \\
\hline Manufacturing & $\begin{array}{c}.8602 \\
(.0438)\end{array}$ & $\begin{array}{l}0.6712 \\
(.2455)\end{array}$ & -264.260 & 26.05 \\
\hline Transportation\&PUtilities & $\begin{array}{c}.6226 \\
(.1319)\end{array}$ & $\begin{array}{l}0.9268 \\
(.4840)\end{array}$ & -308.607 & 19.18 \\
\hline Wholesale trade & $\begin{array}{c}.9261 \\
(.0342)\end{array}$ & $\begin{array}{l}0.1673 \\
(.0912)\end{array}$ & -306.673 & 45.75 \\
\hline Retail trade & $\begin{array}{c}.8775 \\
(.0621)\end{array}$ & $\begin{array}{l}0.2071 \\
(.1409)\end{array}$ & -349.340 & 59.31 \\
\hline FIRE & $\begin{array}{c}.9376 \\
(.0315)\end{array}$ & $\begin{array}{l}0.1192 \\
(.0706)\end{array}$ & -321.858 & 36.33 \\
\hline Services & $\begin{array}{c}.6382 \\
(.1845)\end{array}$ & $\begin{array}{l}0.5413 \\
(.4327)\end{array}$ & -348.154 & 28.19 \\
\hline
\end{tabular}

Notes: QML estimates with 611 observations (1946:02 to 1996:12). The asymptotic standard errors are calculated based on Ruiz (1994). The Box-Ljung $Q(p, q)$ statistic where $p$ equals the number of lags and $q$ equals $p+1$ minus the number of parameters is tested against a $\chi_{q}^{2}$ distribution. The critical value at 95 percent level is 32.67 . 
TABLE 4 --Normality TeStS ON THE ERror TERM IN EQUATION 3

\begin{tabular}{|c|c|c|c|}
\hline & \multicolumn{3}{|c|}{ Fuller-transformed } \\
\hline & Skewness & Kurtosis & B-S \\
\hline Total nonfarm & 3.5626 & 0.0768 & 3.6394 \\
\hline Government & 0.8103 & 0.6165 & 1.4267 \\
\hline Mining & $212.87 * *$ & $737.57 * *$ & $950.43 * *$ \\
\hline Construction & 0.0490 & $7.4172 * *$ & $7.4662 *$ \\
\hline Manufacturing & 1.5114 & 3.5180 & 5.0294 \\
\hline Transportation\&PUtilities & $36.008 * *$ & $43.132 * *$ & $79.140 * *$ \\
\hline Wholesale trade & $17.853^{* *}$ & 1.703 & $19.556^{* *}$ \\
\hline Retail trade & 2.1400 & $7.2417 * *$ & $9.3817 * *$ \\
\hline FIRE & $9.4349 * *$ & $4.7137^{*}$ & $14.149 * *$ \\
\hline Services & $19.919 * *$ & $6.6334 *$ & $26.552 * *$ \\
\hline
\end{tabular}

Notes: The skewness and excess kurtosis statistics are tested against a $\chi_{1}^{2}$ distribution. The Bowman-Shenton (B-S) statistic for normality is skewness plus kurtosis, and is distributed approximately as $\chi_{2}{ }^{2}$ under the null hypothesis. Rejections of the nulls of zero skewness, no excess kurtosis, and normality are indicated by asterisks.

* 95 percent $* * 99$ percent 
TABLE 5--QUASI-MAXIMUM LIKELIHOOD ESTIMATION RESULTS UNIVARIATE STOCHASTIC VOLATILITY MODELS

FULLER-TRANSFORMED GROWTH RATES

\begin{tabular}{lcccc}
\hline \hline & $\rho$ & $\sigma_{\eta}^{2}$ & $\log \mathrm{L}$ & $\mathrm{Q}(23,21)$ \\
\hline Industrial Production & 0.8446 & 0.4761 & -327.067 & 45.06 \\
$\quad(.0577)$ & $(.2265)$ & & \\
$\quad$ Index & 0.8071 & 0.5578 & -337.805 & 32.41 \\
Manufacturing & $(.0715)$ & $(.2766)$ & & \\
& 0.8315 & 0.5504 & -315.546 & 32.47 \\
$\quad$ Durable goods & $(.0600)$ & $(.2519)$ & & \\
& 0.8584 & 0.6932 & -249.553 & 34.93 \\
Employment & $(.0439)$ & $(.2507)$ & & \\
$\quad$ Durable goods & &
\end{tabular}

Notes: QML estimates with 611 observations (1946:02 to 1996:12). The asymptotic standard errors, in parentheses, are calculated based on Ruiz (1994). The Box-Ljung $Q$ $(p, q)$ statistic where $p$ equals the number of lags and $q$ equals $p+1$ minus the number of parameters is tested against a $\chi_{q}^{2}$ distribution. The critical value for the Box-Ljung $Q$ at 95 percent level is 32.67 . 

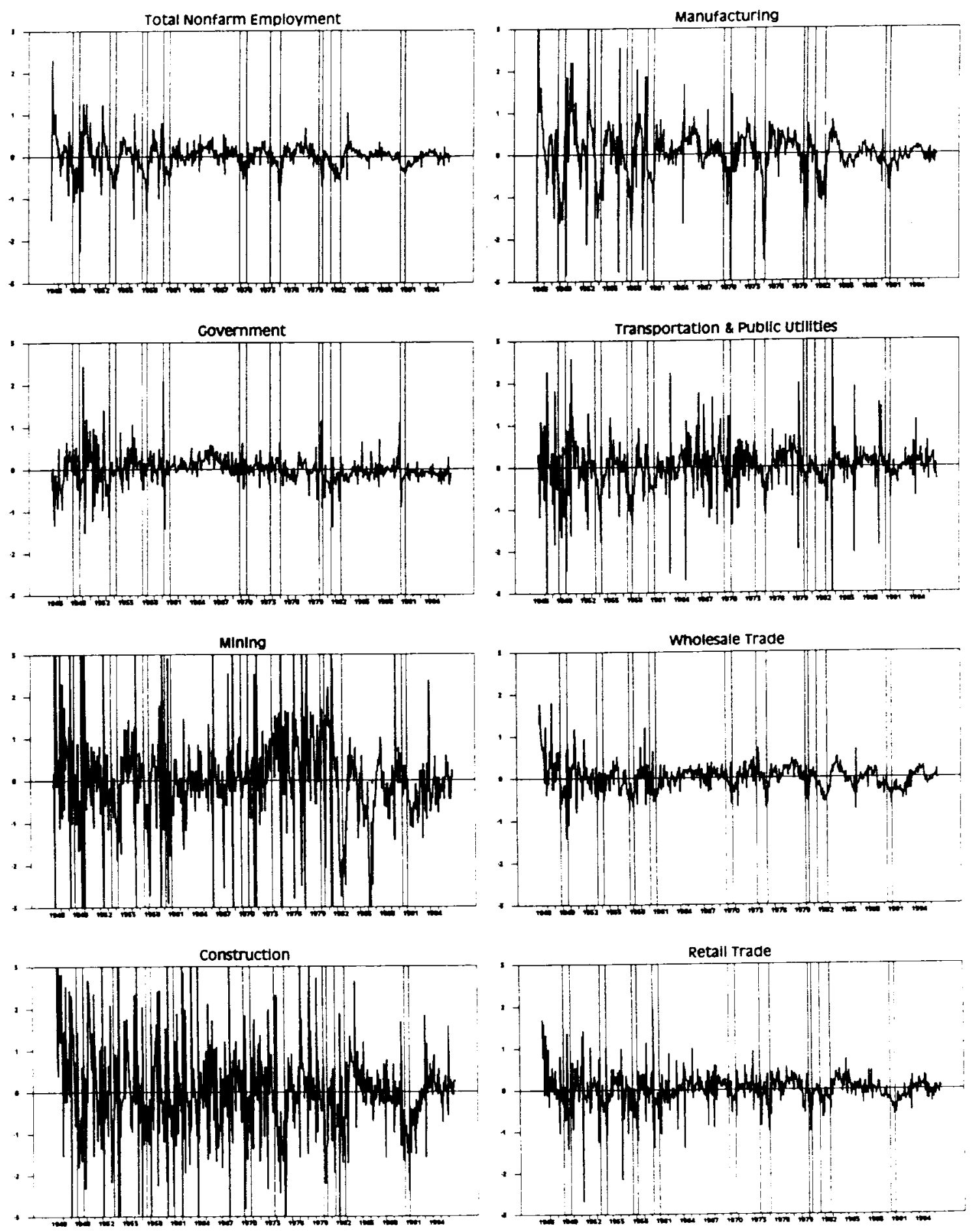

Figure 1. MONTHLy EMPLOYMENT GROWTH RATES, 1946-1996 Note: Growth rates are deviations from mean growth rates. 

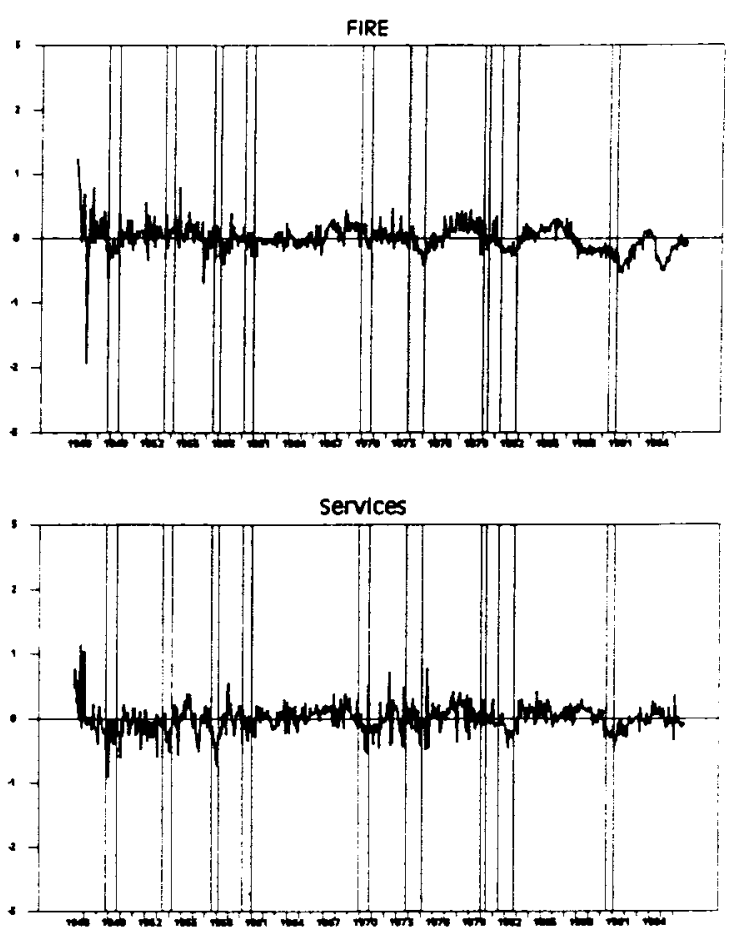

Figure 1 (continued). MONTHLY EMPLOYMENT GROWTH RATES, 1946-1996

Note: Growth rates are deviations from mean growth rates. 

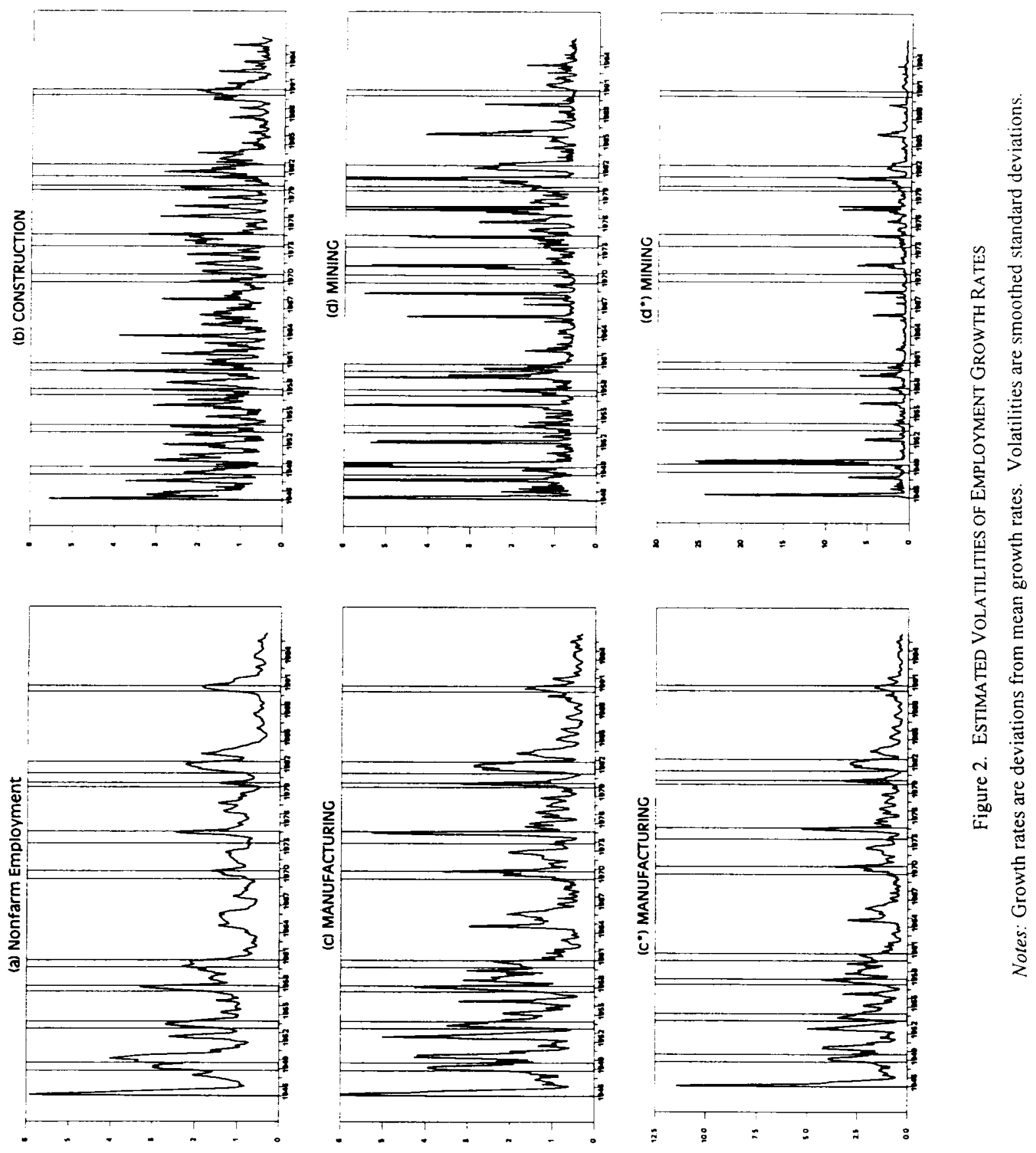

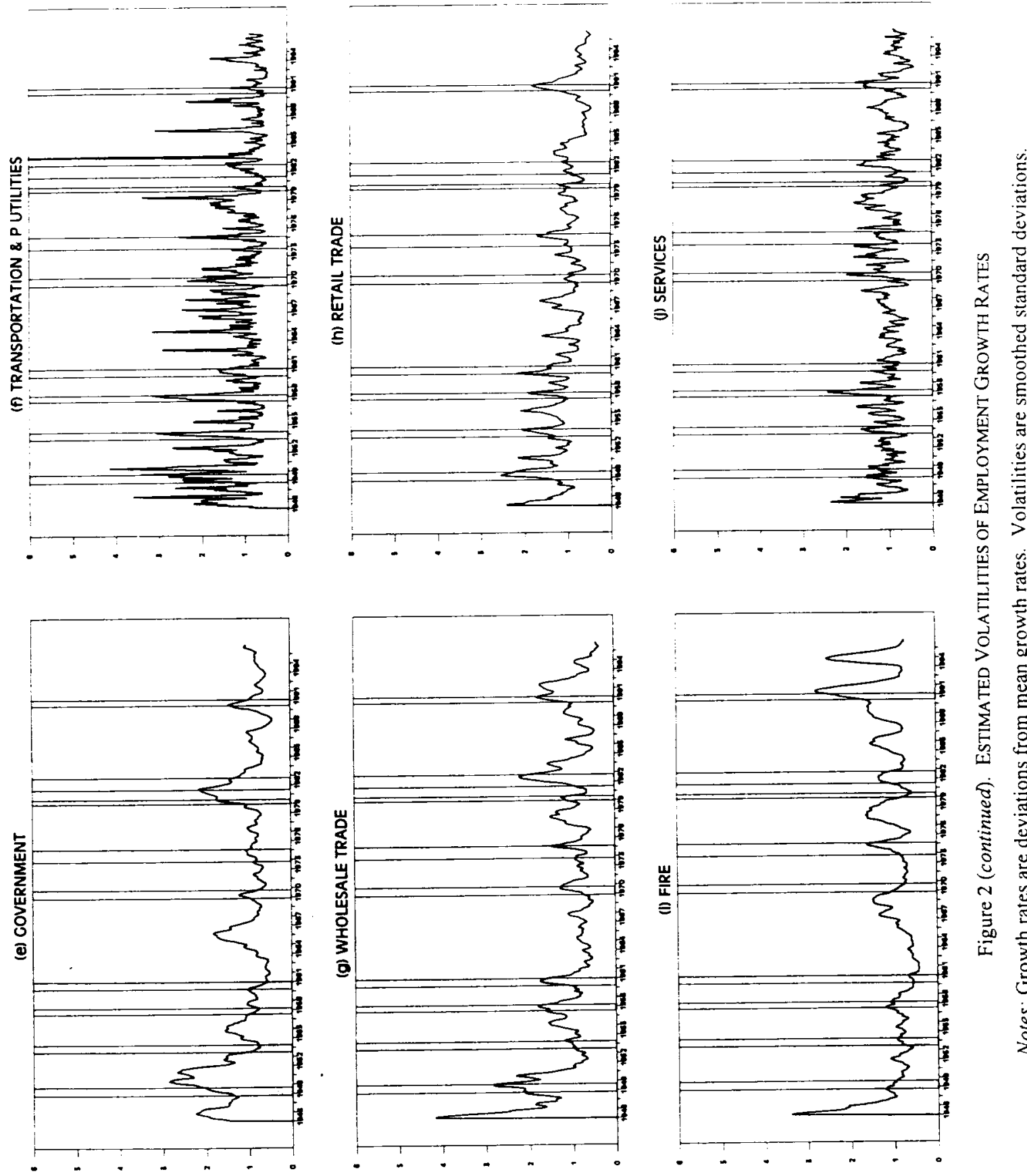


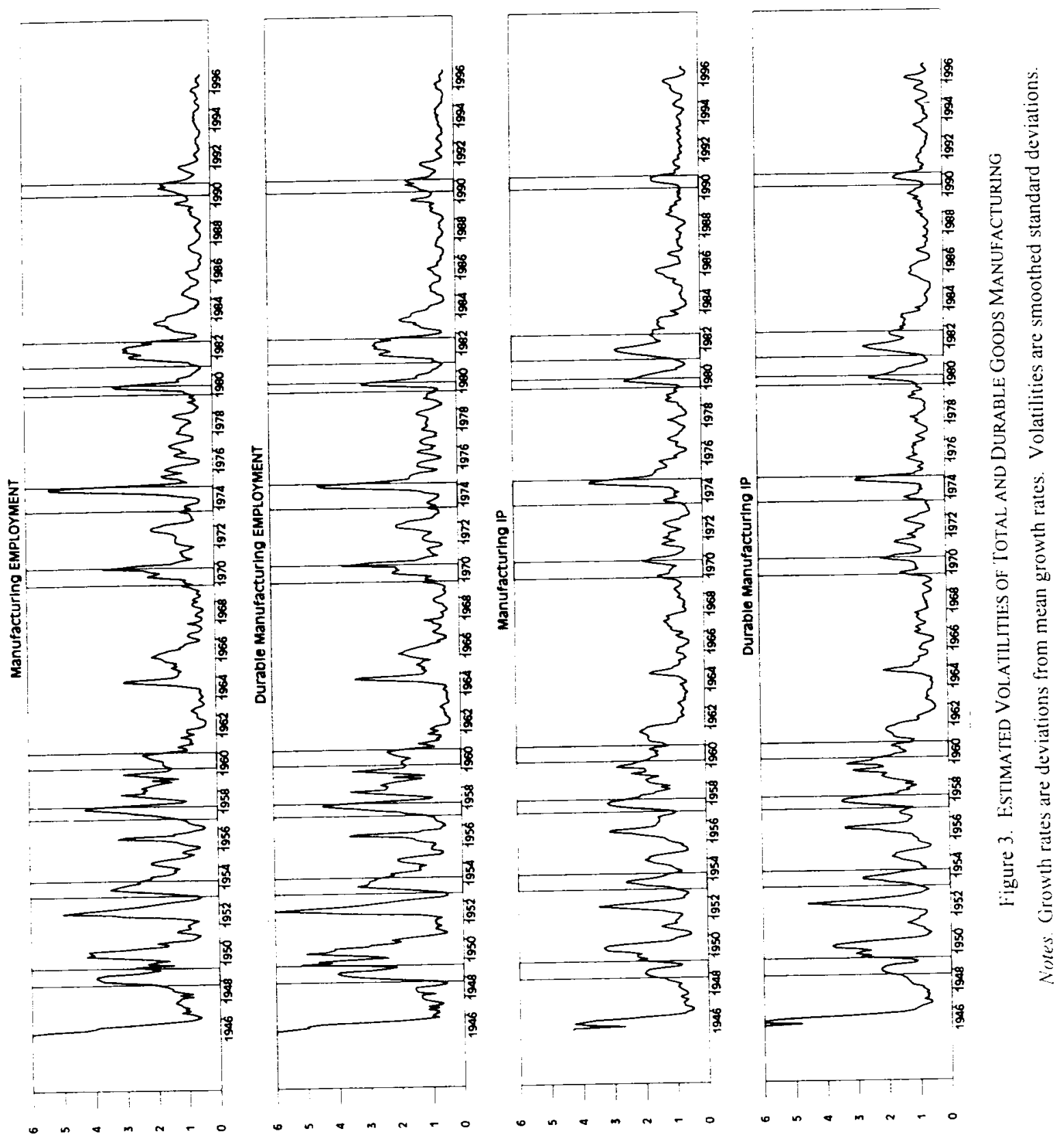




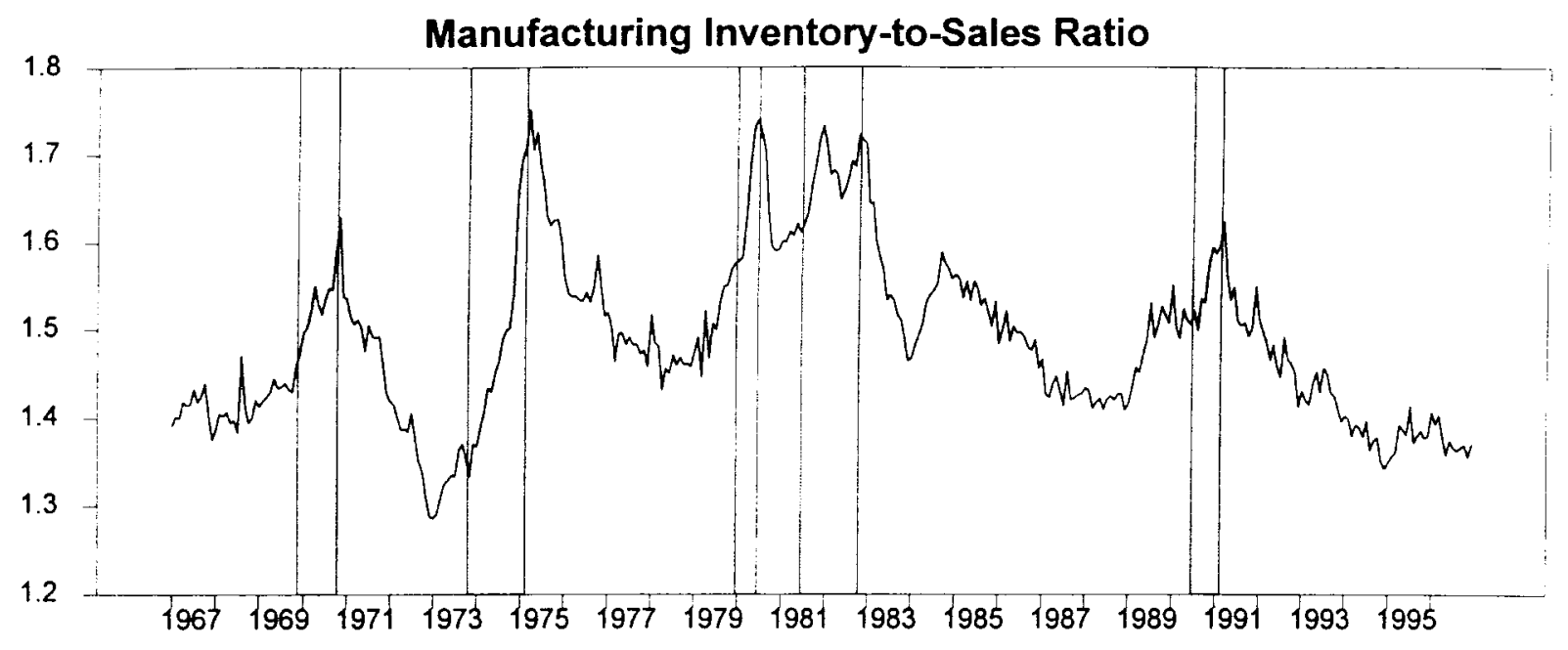

Figure 4. MANUFACTURING INVENTORY-TO-SALES RATIO Source: Census Bureau 